\title{
On Immersive Theatre
}

\section{Gareth White}

This article considers what might be implied in the term 'immersive theatre', asking what kinds of 'interior' audiences are invited to become immersed in. To facilitate my argument I draw on performances by two London-based theatre companies, Shunt and Punchdrunk, as examples of immersive theatre which use architectural interiors: extensive environments which audiences explore in order to find the performance, and sometimes to give performances themselves. I begin with a description of how these physical interiors and the audience member's movement through them becomes part of the dramaturgy of the work, before moving on to a critique of the term 'immersive'. This critique is initially based on analysis of its metaphorical character, using an approach derived from cognitive linguistics, and is developed through Josephine Machon's (Syn)aesthetics and Heidegger's phenomenological aesthetics.

'Immersive theatre' has become a widely adopted term to designate a trend for performances which use installations and expansive environments, which have mobile audiences, and which invite audience participation. So prevalent has the use of this term become in the UK, that theatre journalists have begun to propose that this trend has had its day, accused it of being 'tired and hackneyed already' ${ }^{1}$ and railed at its 'triviality and low-level fascism'. ${ }^{2}$ My question, however, is not whether the work identified as part of this trend has substance and a future, or whether the term designates a significant development in contemporary theatre. Instead I propose to discuss what the term suggests is especially manifest in these performances: immersion. Immersion implies access to the inside of the performance in some way, but what kinds of insides might the term refer to? This article discusses how aspects of immersion occur in seminal, and very 
popular, examples of 'immersive' performances, looks at the importance of interiors to some of these performances and tests some conceptual approaches to the idea of the 'immersive'.

Work designated as immersive theatre, either by companies themselves and their producers or by the press, is diverse. It includes performances that are intensely intimate, as exemplified by Ontroerend Goed's repertoire, ${ }^{3}$ as well as those that allow a little distance between spectator and performance, as with Slung Low. ${ }^{4}$ The work may contain a coherent narrative, as with Zecora Ura and Para-Active in their Hotel Medea (2010), or may be as dreamlike as shows by You Me Bum Bum Train. ${ }^{5}$ There may be the kind of technological mediation seen in Rotozaza's audio-instruction works, ${ }^{6}$ or advance communication with spectators, as in de.bunked's Whose Cloud is it Anyway? (2010). The work may take place in everyday spaces, in the manner of Blast Theory's Uncle Roy All Around You (2003), ${ }^{7}$ or in other found spaces, theatres or galleries. It is likely to be multi-sensory, making use of exploratory experiences of space and relationships to performers, but sometimes also in addressing the senses of touch and smell - as in Mark Storer's A Tender Subject $(2012)^{8}$ - which are not normally significantly part of the semiotic equipment of theatre.

W.B. Worthen, writing about Punchdrunk's treatment of dramatic character in the New York produciton of Sleep No More, is careful to put the word 'immersive' in inverted commas throughout his article, evidently choosing neither to take the concept for granted nor to engage with it directly. Where Worthen does bring the question of immersion into his argument, he uses it to direct attention to the key concern of most theorising about participatory performance; he says: 'Sleep No More immerses its audiences in a paradoxical practice: we write our individualised plotlines in our own movements, but are constructed within the spectacle as realist voyeurs, watchers, and readers, not agents. ${ }^{9}$ As my argument below will show, the feeling of 
making choices within immersive works can be important to their overall sensation, but the question of whether any apparent agency in participatory performance is real or significant is not part of my agenda here. Many of the well known pioneers in different modes of interactive and participatory performance - Augusto Boal, Richard Schechner, or Judith Malina and Julian Beck of The Living Theatre for example - made strong claims for the political potential inherent in the re-ordering of audience-performer relationships. Such claims were based on a perception of conventional audience arrangements as oppressive and the freedom that might be gained by active audiences ${ }^{10}$. Though some immersive theatre has an implicit political agenda (Storer's $A$ Tender Subject, for example, is devised and performed by gay male prisoners and includes images redolent of brutality and victimisation), the claims made for it as a form tend to be more restrained: that it will transform the individual audience member's experience of theatre, without reference to the re-ordering of relationships and experiences outside of it. The rise of immersive theatre might be read as the return of techniques of audience involvement that last captured the imagination of the theatre makers and audiences to such a degree in the sixties and seventies, but this time shorn of political imperatives and allegiances. Contrasting claims for the emancipatory potential of participatory performance have also been made, for example by Nicholas Bourriaud and Jacques Rancière, in which intimate proximity between audience participant and performer is seen as either a liberating factor (for Bourriaud) or the opposite, a 'stultifying' one

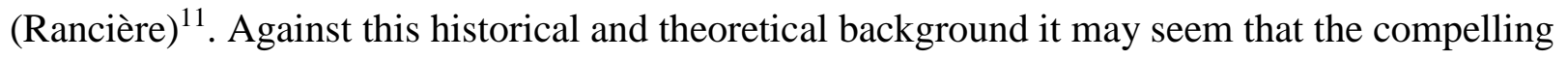
questions about participatory performance relate to the relative agency of the participating audience member, internally within the performance itself, or externally, as the performance experience leads to different relationships beyond itself. However, moving away from debates 
about the capacity for action of the spectator-participant within immersive performance, I look towards a further compelling question: what kind of 'within' there can be.

James Turrell's Bindu Shards, ${ }^{12}$ is a globe-like structure that spectators enter and experience from a horizontal position (stretched out on a bed), as a fifteen-minute 'optical journey'. The active commitment which this piece demands of the 'viewer' is enhanced by the presence of white-coated attendants, who require the signing of release forms and the selection of a 'hard' or 'light' version of the voyage, before access to the structure is allowed. The sense of being inside and surrounded by a work could scarcely be greater than it is inside this bright white sphere, which takes up the whole visual field. But the sphere itself vanishes from sight soon after the light show begins, with its fabulous combinations of colour that seem to have both absolute proximity and great depth, and where the visual field seems to become something else, something simultaneously within and beyond the consciousness of the viewer. Short of asking the spectator to experience a work while under water, Bindu Shards might be the epitome of what is implied by immersion: it has theatrical elements, dialogue with in-role facilitators organising the event and the gesture of surrendering oneself to a clinical/experimental/sacrificial process, but it also makes use of a physical interior, engages the whole body of the spectator/participant, and creates an ambiguous situation whereby it is unclear whether the work is happening around, to, or within the spectator/participant. I will return to Bindu Shards, and the different kinds of inside and immersion it presents to help me articulate ideas about the insides of immersive theatre.

\section{Shunt and Punchdrunk's interior environments}

Shunt ${ }^{13}$ and Punchdrunk ${ }^{14}$ have been particularly successful in respect to their ability to attract large audiences over long runs, their garnering of critical attention and their use of large-scale, 
maze-like found spaces as locations for extensive environmental performances. The attractions of these spaces are obvious: they provide ready-made exploratory landscapes, redolent of other histories, into which performances can be scattered, and in which engagement with the environment can be an important part of the audience experience. Both Shunt and Punchdrunk have made repeated use of disused industrial spaces for their environments. The Shunt collective are very fond of railway arches in east and south east London. Many of their pieces - The Ballad of Bobby Francois (2000), Dance Bear Dance (2003), Tropicana (2004) and Amato Saltone (2006) - have been created in these environments, at sites in London's Bethnal Green and London Bridge. One notable exception, Money (2009), took place in a purpose built environment inside a warehouse, at a short distance from their long-term London Bridge site. Punchdrunk have also used railway arches for Tunnel 228 (2009); as well as empty school buildings for Sleep No More (2003); and warehouses and factories for The Tempest (2003) and Faust (2006). Masque of the Red Death (2007) was performed throughout the extensive spaces of Battersea Arts Centre which, though it is a well known performance venue, inhabits a Victorian municipal building with a rambling, generally unknown and unexplored complex of offices, workshops, attics and halls. Both these companies make work that is site-sympathetic: they create the work for the site where it is to be performed, but without responding directly to that site's history or context. The site contributes an environment for the performance, and significantly affects its atmosphere, but none of the pieces listed above are more than incidentally thematically engaged with the industrial history of London, or the specific buildings which they have adopted. Punchdrunk adapt classic texts, tending to remain faithful to their narrative though distributing scenes around the environment in a way that means few will encounter them in anything like the original order; Shunt use a variety of stimuli, sometimes well known texts such as Zola's 
L'Argent, for Money, but often more esoteric material, and while their audiences tend to follow the performance in a single sequence, their narratives are often fractured, with deliberately puzzling false starts, digressions and lacunae.

Shunt's long-term base under London Bridge station, which they inhabited from 2004 to 2010, was accessed through a single door, located in a small archway off the concourse between the Underground station and the mainline railway station. The door was unmarked - looking as if it would provide access to storage or maintenance areas serving the stations. When in use for a performance it remained unmarked, audience members were either 'in the know' or would be directed there by the company's website; walk up trade was not actively encouraged. The door provided entrance to a small room where tickets were sold and checked. For Tropicana, the first piece shown there, the audience were led in small groups from this room into a further space that appeared to be a large lift, thereby creating the illusion of descending further below the station. Thereafter, they were walked along an extensive series of dimly lit arches, at the end of which they found a spot to watch the beginning of 'the show'. This series of coups de théatre - the theatre disguised as a storage room, the fake lift, the long, long walk into the depths of the normally invisible space under the station - was an adventure into the interior of the industrial city, and was key to creating the atmospheres of mystery and unease and the contrasts between the airy and the subterranean that the piece exploited.

Interiors were also important to Money. Unusually for a Shunt work, this piece was performed inside a purpose-built structure housed in a large warehouse, and though it was inside such a building, it was the interior of the designed-and-built structure which served to frame the audience's experience. The structure was three stories high, menacing but ambiguous, resembling a railway wagon, or perhaps a furnace, or even a war machine of some kind. In what 
remained of Zola's narrative, this machine seemed to be the innovation that propelled characters (and, by implication, the audience) to riches, creating a stock market bubble and subsequent crash. Scenes took place on all of these three levels, with the audience moving between the middle and the upper levels, sometimes occupying a room with performers to watch and/or interact with them, other times looking through transparent floors and ceilings into scenes above or below them. These variations of physical proximity and environmental interpenetration replaced the larger scale environmental explorations of the company's earlier work. Interior spaces, then, and impressions of being on the inside of somewhere that is normally hidden, have been consistently important to Shunt's work.

Punchdrunk's most striking innovation is the mask that they ask spectators to wear for most of their shows. This has a number of effects on audience behaviour and on the performance experience: disinhibiting interaction and exploration, rendering other audience members less visible, making the gaze more focussed and directed..$^{15}$ Moreover, the company are innovative in their approach to the scale and detail of their environments: the way they structure (and deconstruct) narratives by distributing them through those environments, and their use of one-onone performances within this structure. Like Shunt, the environments Punchdrunk inhabit are usually large, including many rooms and corridors. Typically an audience will move from place to place, either individually or in small groups, movement that often accelerates as performers follow narrative paths and spectators pursue them. The feeling that there is more to see in the next room, and that there is always a danger of missing something, propels this movement. The moment-to-moment 'what happens next?' of conventional narratives is replaced by the 'where is he going?' and 'what's in the next room?' The spaces of the environment are often dressed as the private spaces of the characters, and are open to unhindered investigation. Masked spectators are 
generally ignored and treated as if they are invisible: the Stanislavskian 'circle of attention' with its 'solitude in public' is often enforced. ${ }^{16}$ Yet spectators are able to approach and examine them, invading the performers' space while they accomplish the complex job of telling and inhabiting a story, but doing so in among the spectators and without the aid of a clearly differentiated space. The use of interior space by Punchdrunk is developed through these invitations to explore and to try out different relationships and points of view in relation to the performance and its setting.

It is clear, then, that these works are immersive in an almost literal way - they require the audience to move within the space occupied by the performers, a space that is replete with associations and which becomes performative in new ways in consequence of the audience's presence within it. The range and variety of these performative relationships between spectators, environment and performers, and the nuances they bring to spectator experience, suggests why these strategies have become so popular with some audiences and practitioners. As with Bindu Shards, the physical relationship of the spectator to the work is much closer, more direct and potentially more intense. But this is not all there is to the notion of an immersive work: we talk of 'immersing ourselves' in other experiences - new situations, cultures, environments - as well as in more conventional art works like books and films, when we want to commit to them wholeheartedly and without distraction. The implication of the term 'immersive theatre' is that it has a special capacity to create this kind of deep involvement. Therefore, it is arguably worth looking a little more closely at what this everyday metaphor might mean. 


\section{Image schemata and immersion as metaphor}

Cognitive linguists examine how everyday metaphors exhibit important connections between spatial and sensorimotor experience and cognitive structures. As Bruce McConachie and F. Elizabeth Hart state in their introduction to Performance and Cognition:

According to the 'embodied realism' of George Lakoff and Mark Johnson, [...] mental concepts arise, fundamentally, from the experience of the body in the world. As 'neural beings,' humans must make meaning within certain 'spatial relations' and 'bodily action' schemas along with other mental constructs arising from the interplay of experience and patterning in the brain. 'Primary metaphors' flesh out the skeletal possibilities of many of these foundational schemas. ${ }^{17}$

In this theory complex or non-concrete phenomena are described through images drawn from these spatial and bodily schemata, showing how fundamental metaphors are to everyday thought. In Philosophy in the Flesh, ${ }^{18}$ Lakoff and Johnson - key figures in the field cited by McConachie and Hart - provide an extensive analysis of the metaphor 'Love Is A Journey', which they propose as a conflation of three primary metaphors: 'A Relationship Is An Enclosure', 'Intimacy Is Closeness' and 'A Purposeful Life Is A Journey'. The latter, key metaphor is based on the schema of 'source-path-goal', which is founded on the sensorimotor experience of directed travel as it is discovered at an early age. Neither life nor love in and of themselves necessarily have a path, a goal or a direction, but these metaphors allow us to think and talk about their meaning more extensively and creatively. The other two metaphors conflate with this to produce an image of the relationship as a vehicle on this journey; the 'entailments' of this metaphor are what produce the structures of thought made available through it: 
The Love Is A Journey Metaphor

Love Is A Journey

The Lovers Are Travellers

Their Common Life Goals Are Destinations

The Relationship Is A Vehicle

Difficulties Are Impediments To Motion ${ }^{19}$

Lakoff and Johnson follow this with a series of thirteen familiar and conventional expressions in contemporary American English, about relationships, all based on these entailments: from 'It's been a long, bumpy road' to 'The marriage is out of gas'. Thus, this kind of idiom is not just a way of expressing a complex idea through a striking image, nor even of stating an understanding that is held and understood at a deeper level: the idiom and the imagery through which it is expressed can make up the structure of thought that is available for thinking about important phenomena. McConachie and Hart have shown how this project can be extended into performance studies, to complement phenomenological strategies for performance analysis (Hart), or for the rebuttal of Lacanian approaches to performance history (McConachie). ${ }^{20}$

I want briefly to apply Lakoff and Johnson's method of dealing with metaphors - the identification of the higher order metaphors from which they derive and the entailments which follow them - to propose that 'Art Is Immersive' is a metaphor that conflates two higher-order metaphors: 'Artworks Are Containers', and 'Experience Is A Body Of Water'. Following Lakoff and Johnson's style, these metaphors might have the following entailments:

The Artworks Are Containers Metaphor

Artworks Are Containers

Artworks Have Insides And Outsides 
The Meaning Of The Work Is Inside

Watching/Viewing Reveals What Is Inside

This metaphor and its entailments are expressed in everyday language in which we try to 'get something out of' art works or experiences, as well as 'getting into' them and finding things in them.

The Experience Is A Body Of Water Metaphor

Experience Is A Body Of Water

Experience Flows Around Us

Experience Can Be Shallow Or Deep

Experience Can Be Dangerous

This gives rise to familiar expressions such as 'throw yourself in', 'sink or swim', 'keep your head above water', and 'go with the flow'.

'Art Is Immersive' is a metaphor that constructs the experiential aspect of art in a way that draws on a concept of the liquidity of experience and the interiority suggested by the containercharacter of artworks. Its entailments might look like:

\section{The Art Is Immersive Metaphor}

Art Is Immersive

Art Experiences Are Shallow Or Deep

Successful Art Experiences Are Deep

This metaphor appears in the way we speak about performing, in the way actors speak of 'getting into the role', for example, as well as in straightforward statements about becoming immersed in a book or a play as receiver of the work. When we use this metaphor to describe a style of performance further entailments might follow: 


\section{The Immersive Performance Metaphor}

\section{Performance Can Flow Around Us \\ Participation Can Sweep Us Away \\ Participation Makes Waves In The Performance}

The value of this approach to metaphors is partly that it draws attention to how we express what we value in phenomena, as in the relative depth and shallowness of experiences in general and art experiences in particular. And, more importantly, it allows us to grasp how these ways of thinking and ways of speaking are based on foundational schemas which do not, in fact, provide the basis of the phenomena in question, but are the basis of our physical and sensorimotor understanding of our world. Amongst the foundational schemas lurking behind these metaphors are: 'containment/containers' and 'solid/fluid substance'. Experience is not a liquid, but if it can be thought of as a thing at all it is something immaterial and immensely difficult to talk about, except by using metaphorical language like this. Whilst many art works may have some kind of containment character to them - the covers of a book, the frame of a painting, or James Turrell's white globe - the relationship of a reader/viewer/participant to the substance of the work is only incidentally related to this character. We do not reach into a work and take something out of it, except in a metaphorical sense.

But when we move within the physical space of a work - as we do in immersive theatre are we doing something that is beyond the metaphorical? To what extent is the metaphorical sense of the nature of art experiences as things that we can submerge ourselves in and surrender ourselves to superseded by a direct analogy between the movement into the physical interior of a work and submerging in water? To some extent the use of interiors in many immersive performances justifies the use of the term 'immersive' in a way that is non-metaphorical; but it is 
important that the values implicit in the metaphor remain: that we move within the art work, intimately close to it, but still distinct from it. To be immersed is to be surrounded, enveloped, and potentially annihilated, but it also is to be separate from that which immerses. The entailments of the Immersive Performance Metaphor maintain a separation between the subject and the work (as a fluid and a body swimming in it), and they imply that there is a relationship between a work as an exterior thing - for all its dangerous intimacy - and a distinct, swimming subject. The same propositions might be entailed if we read 'immersive performance' as an analogy rather than a metaphor.

Turrell's Bindu Shards again serves as an example of another model of immersion. In this piece the visual material experienced by the spectator does not appear on the surface of the dome within which the spectator lies, it is created within the eyes of the spectator by the interplay of coloured light reflecting at different angles and intensities within the dome, facilitated in part by a process known as the Purkinje effect. ${ }^{21}$ In a very real sense, then, the spectator is not inside the work, in the way that the body is inside the dome, but the work is inside the spectator. We might see in this an image of spectator or audience response to all art works: the works are nothing without the 'eye of the beholder' (and we might substitute here: ear, body, sensibility).

If the performance does not just surround us but occurs within us then we are part of it, and it ultimately becomes part of us at the moment of performance. The term 'immersive', however, maintains a subject-object divide, as it implies (and structures our thinking about the experience towards) a subject inside the object, not interpenetrated by it. How, though, do we account for the interpenetration of works of performance into the body of the audience member, when specific, anomalous phenomena like the Purkinje effect are not at work? 


\section{A (syn)aesthetic approach}

Josephine Machon, in (Syn)aesthesia: Redefining Visceral Performance, ${ }^{22}$ cites Shunt and Punchdrunk as examples of what she identifies as an increasingly prevalent mode in contemporary performance, which addresses multiple senses simultaneously, rather than addressing itself primarily to conscious thought. Her identification of 'visceral performance', and her approach to interpreting it, is especially persuasive in relation to immersive performance: the proximity of performing bodies, along with the physical interaction of the spectator with the environment mean that the experience of the work will be more than usually multi-sensory, and that bodily movement will be one of the senses addressed. One of the key propositions of her '(syn)aesthetics' is that the: 'fusing of sense (semantic 'meaning making') with sense (feeling, both sensation and emotion) establishes a double-edged rendering of making-sense/sense making, ${ }^{23}$ thus she places the site of response throughout the body rather than in a mediation by the bodily machinery of the senses on behalf of the mind or brain. There is more to her fusing of terms than word-play: it entails that the subject that makes sense of its experience is constituted by those bodily senses, rather than distinct from them. In Machon's theory '[t]o experience synaesthetically means to perceive the details corporeally'. ${ }^{24}$ (Syn)aesthetics proposes that the work happens to the body of the spectator, inviting a more direct address to that body by performance and performance makers. Immersive performance addresses itself to these bodies in an unambiguous way by locating them within the performance space, in proximity to performers, and inviting them to move and interact. This theory offers some terms with which to address what it means to be 'immersed' in performance, but which avoids what is entailed by the metaphor of immersion. 
As my earlier overview of Punchdrunk and Shunt attests, bodily sensing is vital to sense making in their respective works. The restriction of vision, encouragement of movement at different speeds through very different environments, and variations of dense proximity to other spectators with individual encounters and moments of solo exploration, are fundamental to the physical experiences of such performances, and the sensations gathered in this way cannot be separated from those acquired by watching and listening to the performance. It should be noted, however, that the 'fusing' of these two different sense-modes is not always successful: many people have found this form immensely frustrating, that these layers of physical experience interfere with the process of reception and response to a performance that seems to be on offer, yet always in some way out of reach. In Shunt's work the performance is usually 'delivered' to the audience in a more sustained and consistent way: they are not required to seek it out or to wander through it unguided. That said, the variations of physical relationship between audience members and performers, other audience members and to the architecture of the space are striking and important to the overall effect of their work. For instance, the variety of interiors offered in Money develop a theme of interiority in the narrative - as the piece progresses the audience follows a budding entrepreneur as he struggles to gain access to an inner circle of potential investors, and as he becomes accepted in their company he penetrates deeper levels of privilege and intimacy, echoed in the spaces in which he is seen. At one point, spectators watch as, two floors below in 'the machine', the entrepreneur shares a sauna with an anonymous senior investor, mysterious and inaccessible to him prior to this. The series of moves from outside to inside, views of insides and views from insides to outsides give a corporeal corollary to the progress of this character as he makes his way deeper into the physical machine and the social machine of high finance. The play with interiors does not match the thesis of Zola's novel 
allegorically, but provides a system of echoes and suggestive images delivered through the body's presence in the performance space.

Machon's ideas help us to understand the corporeal character of audience experience in these works, particularly evident in their spatial strategies and also in their use of direct interaction between performers and audience members. Speaking to, following or dancing with a performer creates a physical relation, and a sense/sense dynamic which will inform any response or interpretation. But it does not explain another facet of the sensations they generate: the feeling that if we work hard at our role in them, and pursue the action and the performers, we will gain access to the interior of the drama itself. Machon helps to explain how we perceive work like this where the physical and interactive relationships offered in it are complex and multi faceted, but does not explain what we will find if we are tempted to pursue the inside of the work even further, or where we will meet the boundary between the work and ourselves as we pursue it.

\section{Pursuing the inside of the immersive}

Interaction between performers and audience in Punchdrunk's work has developed from their early use and development of the one-to-one encounter. They have always included space for planned and unplanned interaction, from the physical contact that inevitably occurs as performers move around pursued by crowds of spectators trying to connect elements of the plot and to ensure they see more of the action, to sequences where partner dancing is invited or where a performer acknowledges the presence of a spectator in the space in more subtle ways, by mirroring their movement perhaps, or playing hide and seek. Increasingly, though, these encounters happen in private spaces, away from other audience members, and afford a brief oneto-one moment within the performance as a whole. 
In Faust and Sleep No More the audience had access to characters' bedrooms, while in Masque of the Red Death there was a theatre dressing room, hung with costumes and a row of mirrors. Being allowed to follow characters into these intimate spaces constitutes another facet of the company's preoccupation with interiority in these immersive environments: it allows for a feeling of being behind the scenes, and of being able to see what is otherwise hidden. But it is also a matter of adding apparent layers of depth to the drama itself, as well as to the presentation of a fictional space: layers that seem to be accessible to audience members, should they pursue them vigorously enough. The combination of the need to make an effort to find the most enjoyable elements of the performance, and the provision of intimate encounters for only a lucky few audience members, works to create a sense that there are always further mysteries to be discovered. This layer of interiority can lead to a feeling that the one-to-one will be the fulfilment of the desire to follow the drama deeper into the environment, that it will let you inside the drama. But the interesting issue is what happens when spectators catch up, when they find their way into an intimate encounter, and how this encounter is scripted and structured to satisfy the desire to be 'inside', without over-taxing the performer and the audience-participant's abilities to create moments of performance, even drama, with each other. The one-to-one encounter has become a particular focus for this in Punchdrunk's work, and provides a site where the desire to access a deeper encounter with the fictional space of the performance generates tension with the actualities of interactive performance.

A brief account of my own experience of a one-to-one encounter can illustrate and facilitate a closer examination of this issue. This occurred in Tunnel 228, a Punchdrunk show that involved fewer performers than they usually use, but more installations created by a group of collaborating artists. Wandering around the large, dark and rambling environment, I discovered a 
concealed office, with an actor waiting inside. A dialogue ensued between us in which I was cast as someone acting in the interests of the menacing, industrial, apocalyptic institution conjured by the installations. I was conscious of both cooperating with the actor in maintaining the fiction of the situation, and of resisting the malevolent designs his character tried to draw me into. I was pleased with the way I played this game - with some of the lines I invented for myself, as well as my evasiveness - and was also delighted to have an encounter all of my own in a space not seen by most of the audience. While this scene would unfold differently for each participant, it provides an example of an interaction which addresses the audience-participant through verbal, scenic and physical means, placing them bodily at the centre of a scene which relies on their presence and their contribution. The insides operating here are threefold: environmental, as the office is the most secret interior of the interior space of subterranean tunnels in which the event took place; fictional, as the performer inveigled me into the inner circle of his sinister organization; and theatrical, as I move from spectator to performer roles, outside to inside the drama. As with Shunt's Money, Tunnel 228 has (in this one-to-one, at least) a complex set of immersions, echoed in its themes and in its participatory strategies.

What do these interior aspects amount to? The scene revealed plot-related information, inflected by the scenic environment and its corporeal effect on me; but my inclusion in the fictional world at this level did not, of course, give me a genuinely privileged insight. My expanded perception of this world was a result of the imaginative filling-in of gaps, as Wolfgang Iser tells us is the case for the reception of fictional works in general. ${ }^{25}$ The scene also led me to behave like an actor: to adapt my behaviour to support and create a dramatic fiction through interaction with another person. The complicity the performer and I found in this interaction despite the competing agendas that we seemed to bring to our roles - was of the sort that is 
usually at work to present a consistently dynamic fiction for another group: the audience. There was no audience; I, as the representative of the audience, had become a performer in the most thoroughgoing way possible, in that my transformation had eliminated the separate role of audience from the theatrical event for the duration of this interaction. The performer and I were audience to our own performances and to each others', in a way that I found intriguing, though also a little embarrassing. ${ }^{26}$ I felt a little of the humiliation of the players' reaction in Stoppard's Rosencrantz and Guildenstern are Dead, who: 'pledged our identities, secure in the conventions of our trade; that someone would be watching. And then, gradually, no one was. We were caught, high and dry'. ${ }^{27}$

Pledging myself to this brief performance was enjoyable, but afterwards I was aware that it was given for my own benefit only - or worse, that my part in it involved an attempt to impress my anonymous collaborator. If I had found an interior, it was a very ambiguous one. If we, as excitable spectators, stop to think of what the inside of a piece of drama is, we will realize that it is not a place of substance, but the set of surfaces that provokes depths of feeling in us as audience. Though the experience of this one-to-one was exciting, and added nuances to my impressions of the work as a whole, the inside it brought me to was the inside of the production of the drama rather than the inside of the drama itself. The question remains as to what else, if anything, might be found on the inside of the work, if such an inside exists.

\section{A Heideggerian ontology}

Heidegger's essay 'The Origin of the Work of Art ${ }^{28}$ presents an alternative way of accounting for what is revealed through successful art experiences; and as I am ambitious for the potential of immersive performance, I will apply its logic to the case in hand. In the ontology set out in this 
essay, Art (the capitalization is important as it distinguishes a potential beyond the everyday 'art world'), is an event of truth. Heidegger's conception of truth is complex, but it centres on the 'unconcealment' of things in their essence: and an unconcealment of this kind is possible in a successful work of Art. The sense in which the occurrence of truth is a process and an event is suggested in the following summary sentence: '[t]he essence of truth is, in itself, the primal strife in which that open centre is won within which beings stand and from which they set themselves back into themselves'. ${ }^{29}$ Truth is not the stable situation of knowing what statement corresponds with what reality, but the space in which 'beings stand forth', and just as importantly, from which they inevitably fade from view. The value of artworks is that they have the potential to create the 'open centre' where such an unconcealment can occur.

What might I say is 'unconcealed' for me at this moment in Tunnel 228? In my account above it might be something which drew together the disparate threads of the installation as a whole, giving them a consistency not previously perceived. It might also have been something about myself, as a person likely to respond to this invitation, and to respond in certain ways. Crediting the processes of this interaction for subtlety and substance, I might argue that they cleared the space for an interaction between the elements of self, scenographic environment and staged interaction to stimulate a perception about my own implication in a vastly integrated social and industrial system.

However the analysis possible on these terms offers little more than what could be achieved with everyday terms. Pursuing Heidegger a little further might show something more. The 'strife' mentioned in the quotation above is more explicitly explained as the conflict between 'earth' and 'world': between the concealed and the revealed. The following passage gives some sense of 'world' as the appearance of things to human beings (beings-in-the-world): 
The world worlds, and is more fully in being than the tangible and perceptible realm in which we believe ourselves to be at home. World is never an object that stands before us and can be seen. World is the ever-nonobjective to which we are subject as long as the paths of birth and death, blessing and curse keep us transported into Being. Wherever those utterly essential decisions of our history are made, are taken up and abandoned by us, go unrecognized by us and are rediscovered by a new inquiry, there the world worlds. ${ }^{30}$

In Heidegger's characteristic language, both strenuously precise and allusive, we find a play on words in which subject and object are meaningless unless seen as terms in the process through which Being happens for us. And earth is not the opposite of this, but its hidden counterpart that dwells within the very same things which come into being for us as world. If 'world worlds', that which it worlds is both ourselves and anything else brought momentarily into a clear space of perception, out of the obscurity of earth. In this account Art is a matter of 'setting up a world and setting forth of earth', where world is that in which being is always already engaged, and earth is the immanent material that forms the background of world. This setting forth is not a completed process of absorbing it into world, but the shocking realization of the space that remains between the two realms. Heidegger says that the opening up of this space leads to strife, in a positive though uncomfortable experience for the one who meets this experience.

In immersive work this strife occurs with the apprehension of the spectator/participant in a process that is unlike everyday lived experience, but where the material of everyday lived experience - our bodies and our social selves - comes forth as world. Is this an inside? Earth is 
what is opened in any art encounter, but it is not the inside of the work, it is the inside of what is employed in the work of art as it becomes world. And in this sense it is as much made up of what we bring to the work as being-in-the-world as what the artists/performers bring to it. In the case of participatory work we add a layer to this in the sense that we are part of what the artist brings, and we meet our own world-earth strife more intimately as we are evidently present in the work as well as in the event of its opening.

'Immersive theatre', then, is an inviting but faulty term to use to describe the phenomena it currently designates. Immersive theatre often surrounds audience members, makes use of cleverly structured interiors and ingenious invitations for them to explore, addresses their bodily presence in the environment and its effect on sense-making, and teases them with the suggestion of further depths just possibly within reach. But it has no strong claim to either creating fictional or imaginative interiors in a way that is different in kind than in more conventionally structured audience arrangements. Just as for the spectator/participant of Bindu Shards, the audience experience of immersive theatre is enhanced by the excitement of the procedures and processes which take them into the performance environment and invite them to engage with it; but this sensational aspect can also suggest access to hidden depths which cannot be reached, while distracting from the potential depth of an experience which (again as with Bindu Shards) happens as much within the participant as in the elaborately constructed environments around them. The image of the spectator immersed within the work, preserving as it does the distinction between an exterior work and the perceiving subject, describes only work which fails to achieve what Heidegger would call the moment of strife, where a truth is 'unconcealed'. Ontologically speaking immersive theatre can only achieve what other forms of performance can achieve: a 
relation in which the event of a work of art occurs between its material being and the person who encounters it. If it has claims to make - as well as its persuasive claims for having found new and excitable audiences - they must be to do with its potential to stimulate these relations, rather than with creating realms of experience not available in other kinds of work.

${ }^{1}$ Charlotte Higgins, 'Immersive Theatre: Tired and Hackneyed Already?', The Guardian Blogspot, 7 December, 2009, http://www.guardian.co.uk/culture/charlottehigginsblog/2009/dec/07/theatrepunchdrunk (accessed 29 January 2012).

2 Michael Coveney, 'Stage Directions: Immersive Theatre', Prospect, 19 August, 2010, http://www.prospectmagazine.co.uk/2010/08/you-me-bum-bum-train-one-on-one-theatre/ (accessed $29^{\text {th }}$ January 2012).

${ }^{3}$ Particularly The Smile off Your Face (2003) Internal (2007) and A Game of You (2010). Internal begins as a kind of performative speed-date, and becomes a provocative, manipulative dialogue that can continue by post after the end of the performance itself. Ontroerend Goed are based in Gent, Belgium.

${ }^{4}$ For example They Only Come At Night, a vampire story (2007) or Anthology, an intertwining set of seven different narratives (2010). Slung Low are based in Leeds, UK.

${ }^{5}$ You Me Bum Bum Train is Kate Bond and Morgan Lloyd's evolving single-audience-member journey, different versions of which have been presented since 2004 .

${ }^{6}$ For example Etiquette, (2007), in which two audience-participants wear headphones and receive instructions and words to speak, creating a performed dialogue.

${ }^{7}$ In Uncle Roy All Around You online participants viewing a virtual city communicate with live participants who move around a real city, cooperating to find and follow clues.

${ }^{8}$ In A Tender Subject the audience move through a series of spaces containing installations and performances, several of which have powerful smells - disinfectant, mouldy bread, damp, the perfume of a field of growing hyacinths. 
${ }^{9}$ W.B. Worthen, 'The Written Troubles of the Brain: Sleep No More and the space for character', Theatre Journal, 64, 1, (March 2012) pp. 79-97, p. 96.

${ }^{10}$ Boal's propositions about the 'coercive' are most famously expounded in Theatre of the Oppressed (London: Pluto Press, 1979); Schechner’s Environmental Theatre (New York: Applause, 1995) includes a sustained discussion of the potential of participation; The Living Theatre's experiments are well documented in John Tytell's The Living Theatre, Art, Exile and Outrage (New York: Grove Press, 1995).

11 Jacques Rancière's essay ‘The Emancipated Spectator' stringently takes issue with the political potential of participatory performance, but only to insist that the inherent emancipatory potential lies with its opposite: a respectful distance between performer and audience member; Artforum, March 2007, pp.271-291. Nicholas Bourriaud draws on Felix Guattari to conceptualize the emancipatory potential of participatory art as based on its 'thermodynamic' effect on frozen aspects of subjectivity; Relational Aesthetics, (Paris: Les Press du Reel, 2002).

${ }^{12}$ Shown at the Gagosian Gallery, London, October 2010.

${ }^{13}$ For further information about the company see http://www.shunt.co.uk/, (accessed $31^{\text {st }}$ March 2012).

${ }^{14}$ For further information about the company see http://www.punchdrunk.org.uk/, (accessed $31^{\text {st }}$ March 2012).

${ }^{15}$ See my essay ‘Odd Anonymized Needs: Punchdrunk’s Masked Spectator’ for a longer discussion of their use of masks, in Alison Oddey and Christine White, eds, Modes of Spectating (London: Intellect, 2009) pp.219-230.

${ }^{16}$ Constantin Stanislavski, An Actor Prepares, (New York: Routledge, 1989) pp.79-102.

${ }^{17}$ Bruce McConachie and F. Elizabeth Hart, Performance and Cognition: Theatre Studies and the Cognitive Turn (London: Routledge, 2010) p.2.

${ }^{18}$ George Lakoff and Mark Johnson, Philosophy in the Flesh (New York: Basic Books, 1999) p.63-69.

${ }^{19}$ Lakoff and Johnson, p.64. 
${ }^{20}$ Hart's chapter is 'Performance, phenomenology, and the cognitive turn', McConachie's 'Cognitive studies and epistemic competence in cultural history: moving beyond Freud and Lacan', both in McConachie and Hart, ibid, p.52 and p.29 respectively.

${ }^{21}$ The Purkinje effect describes 'the change in colour sensitivity as a visual stimulus [moves] from the centre of the visual field, to the periphery', Jon E. Roekelein, Dictionary of Theories, Laws and Concepts in Psychology (Westport CT: Greenwood Press, 1998) p.92.

22 Josephine Machon, (Syn)aesthetics (London: Palgrave, 2009) p.14.

${ }^{23}$ Machon, p.14.

${ }^{24}$ Machon, p.17.

${ }^{25}$ As cited by Susan Bennett in Theatre Audiences (London: Routledge, 1997) p.44.

${ }^{26}$ Though I am generally immune to the 'ontological queasiness' which Sophie Nield (citing Nick Ridout) feels in these situations: Sophie Nield, 'The Rise of the Character Called Spectator', Contemporary Theatre Review, Vol.18 (4), 2008, pp.531-544.

${ }^{27}$ Tom Stoppard, Rosencrantz and Guildenstern are Dead (London: Faber and Faber, 1968) p.47.

${ }^{28}$ Martin Heidegger, Basic Writings (ed. David Farrell Krell) (London: Routledge, 1993) p.180.

${ }^{29}$ Heidegger, p.180.

${ }^{30}$ Heidegger, p.170.

Gareth White (g.white@cssd.ac.uk) lectures in Applied Theatre and Community Performance at Central School of Speech and Drama, University of London. His PhD in drama comes from Goldsmiths College, University of London, and his research interests centre on audience participation, both in applied contexts and in contemporary theatre and performance. 